\title{
REVIEWS IN PAIN
}

A BPS publication

VOL. 5 - NO. 4 - DECEMBER 2 OI I - ISSN 2042-I 249

OROFACIAL PAIN : PART TW O

E D I T O R I A L

$\mathrm{T}$

This issue of Reviews in Pain explores some of the (putative) neurovascular and neuropathic pains that can affect the craniofacial region: Migraine, Burning

Mouth Syndrome, and Persistent Dentoalveolar pain (PDAP, previously classified as phantom tooth pain, or atypical odontalgia). Mostly these pain entities have a typical presentation that makes diagnosis for the health professional relatively straightforward, but at other times they can present atypically, with other painful co-morbidities, or masquerade as another type of headache or as pathology associated with the dentition (1-7). Compounding this is the possibility that the pain may be secondary to an intracranial pathology. The articles in this issue helpfully illustrate the main presenting features for those readers who are less familiar with these trigeminally mediated pains. They also highlight that in more difficult cases and in the absence of definitive biomarkers, or investigations, more than one discipline may be needed to help establish a diagnosis.

What is clear from the papers is that advances in the understanding of the genomics and pathophysiology of conditions such as Migraine, may help further our understanding of the aetiology of some of the less well understood pains affecting the Trigeminal system. These advances in understanding are likely to translate into better management strategies either through more targeted, or more efficacious, treatment modalities. Such cross-condition and cross-discipline translational advances are clearly urgently needed in conditions such as PDAP, which can have significant psychosocial and economic impacts on the individual.

\section{Justin Durbam BDS, PhD, FDS RCS (OS)}

\section{Diplomate of American Board of Orofacial Pain}

NIHR Academic Clinical Lecturer in Oral Surgery and Specialist Oral Surgeon, Newcastle University

1. Fragoso YD, Carvalho Alves HH, Garcia SO. Association of hemicrania continua and temporomandibular dysfunction: the role of each team player. Headache. 2009;49:1547-1548.

2. Franco AL et al. Migraine is the most prevalent primary headache in individuals with temporomandibular disorders. J Orofac Pain. 2010;24:287-292.

3. Goncalves DA, Bigal ME, Jales LC, Camparis CM, Speciali JG. Headache and symptoms of temporomandibular disorder: an epidemiological study. Headache. 2010;50:231-241.

4. Graff-Radford SB. Headache problems that can present as toothache. Dent Clin North Am. 1991;35:155-170.

5. Namazi MR. Presentation of migraine as odontalgia. Headache. 2001;41:420-421.

6. Nixdorf DR, Velly AM, Alonso AA. Neurovascular pains: implications of migraine for the oral and maxillofacial surgeon. Oral Maxillofac Surg Clin North Am. 2008;20:221-35

7. Spencer CJ, Neubert JK, Gremillion H, Zakrzewska JM, Ohrbach R. Toothache or trigeminal neuralgia: treatment dilemmas. J Pain. 2008;9:767-770.

CONTENTS

P A G E

Migraine Anish Bahra

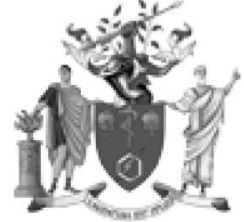

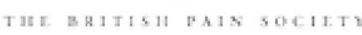

EDITORIAL BOARD

Felicia Cox

Editor

London, Nursing

Prof Sam Ahmedzai

Sheffield, Palliative Medicine

Assoc Prof Nick Allcock

Nottingham, Nursing

Mr Paul Cameron

Aberdeen, Physiotherapy

Prof Eloise Carr

Calgary, Canada, Nursing

Dr Justin Durham

Newcastle, Oral Surgery

Dr Roger Knaggs

Nottingham, Pharmacy

Prof Richard Langford

London, Acute Pain

Dr Mike Platt

London,

Anaesthesia \& Pain Medicine

Dr Jane Quinlan

Oxford,

Anaesthesia and Acute Pain

Prof Jon H Raphael

Birmingham, Pain Medicine

Dr Patricia Schofield

Aberdeen, Nursing

Dr Miles Thompson

Bath, Psychology

Prof Paul J. Watson

Leicester, Physiotherapy

PRODUCTION TEAM

Jacqui Wiles

Leila Taleb

Yves Lebrec 